\title{
浅析新时期企业政工工作面临的挑战和策略
}

陈新

太原市政建设集团有限公司

DOI:10.32629/ems.v2i3.898

[摘 要] 随着我国人民群众文化水平的普遍提高, 各企业对思想政治工作也越来越重视。新时期企业做好工作人员 的思想政治工作对于发展企业文化和人才培养,起着至关重要的作用。随着我国社会主义进入新时代,对企业的思想 政治工作有了更高的工作标准以及要求。本文从新时期企业思想政治工作的重要性入手,详细分析了企业思想政治 工作面临的挑战,并结合实际提出了应对策略,以期能有效的提高企业思想政治工作的开展,并大大提高我国企业的 政治工作水平。

[关键词] 新时期;企业政工工作;挑战;策略

随着我国市场经济新体制的到来, 我国出现了许许 多多的中小企业。企业要想在市场竞争中平稳的发展, 就一定要积极开展政工工作。为了在众多企业中增强企 业竞争力, 就要及时开展政工工作, 加强员工的思想政 治培训工作, 提高员工的综合素质, 这样才能有效提高员 工的工作积极性, 以此增强企业的综合实力并因此提升 企业的竞争力。除此之外, 通过开展企业政工工作还能有 效的保障社会的和谐和稳定, 若是因为企业政工工作开 展不到位, 就会导致企业内部出现问题, 这样的话一定程 度上会对社会和谐稳定造成影响。

\section{1 新时期企业政工工作的重要性}

企业的发展离不开政工工作的支持, 政工工作的成 果不仅能够体现出企业的内部管理制度, 还体现了企业 的文化。随着中小企业的增多,企业市场竞争越来越大, 为了能够在众多企业中脱颖而出, 企业就需要不断加强 政工工作的管理水平。通过有效的政工工作提高企业内
部的管理, 保证工作人员的工作效率, 建立以人为本的管 理理念,从而有效的降低企业成本,提高企业的竞争优势, 充分发挥政工工作在企业内部管理的作用。

在新时期的背景下, 企业政工工作的主要任务目标 就是提高企业员工的政治思想素质与思想认识的水平, 一定程度上能够激发企业员工的工作热情与积极性,使 员工时刻以饱满的精神状态投人到工作中, 让每一位员 工都有一种企业的归属感和自豪感, 重要的是要避免人 才的大量流动,充分发挥出企业政工工作的重要性。从企 业的生产经营层面来说, 最重要的还是保证企业的工作 效率,进而实现经济效益最大化。企业顺利开展生产经营 活动离不开对人才的培养, 因此,人才的思想政治工作一 定程度上影响着企业的发展, 从而充分发挥出企业政工 工作的重要作用。

\section{2 新时期企业政工工作面临的挑战}

2.1 企业没有认识到政工工作的重要性
积极配合工程技术资料管理工作, 并加大彼此监督力 度, 保证技术资料的完整性与精准性。最后, 建筑企业需 要建立相应的技术资料管理规范, 并为此项工作设置专 门的机构, 配备专门的设备设施, 以此来保证技术资料 管理规范被全面精准执行。

\section{5 结束语}

随着我国建筑企业数量的逐步增加, 企业建设水平 等也呈现出参差不齐现象。对于建筑企业而言, 在工程 建设过程中, 会涉及到多方面的管理工作, 而建筑工程 技术管理则是其中的一项重要内容。建筑工程的顺利施 工, 离不开高水平的施工技术, 且在施工过程中, 会应用 到猪都施工技术。作为技术管理人员, 如何结合施工需 要科学合理配备各项技术资源, 就成为决定工程建设质 量与建设效率的关键性条件。以上内容, 分析了建筑工 程技术管理的重要性, 以期引起相关建筑单位的重视。
同时,阐述了建筑工程技术管理原则、技术管理过程中 的问题与解决策略。望能够给相关工作者带来参考, 并 促进我国建筑行业获得可持续性、快速、健康发展。

\section{[参考文献]}

[1]张亿君,黄腾飞.建筑工程技术管理的不足及其 对策[J].中外企业家,2018(33):115.

[2]廖宇.建筑工程技术管理常见问题的探讨 [J]. 建 材与装饰,2019(14):199-200.

[3]王湛雄. 建筑工程技术管理存在的问题与对策 [J].绿色环保建材,2019(08):166.

[4]单静,王宁.建筑工程技术管理当前存在问题与对 策分析[J].建材与装饰,2018(12):199.

\section{作者简介}

姓名: 郑学荣; 民族: 汉; 籍贯: 山东; 身份证号: 370724198707306142 
在企业的发展中,只有通过不断的实践,才能在实践 中认识到政工工作的重要性。但是很多企业在实际管理 过程中, 没有充分认识到政工工作的重要性。随着社会主 义市场不断的发展,给很多企业带来了巨大的发展机遇， 伴随机遇也产生了很多不良的思想。由于企业对政工工 作的不重视, 导致工作人员受到拜金主义和唯物主义的 影响,不断侵蚀着工作人员的思想,促使他们只顾自身利 益, 而不考虑企业的利益, 严重影响了企业的发展,使企业 的政工工作受到了冲击。

\section{2 政工内容明显落后}

近年来,我国已经成为全球最大的经济体之一, 各领 域的经济都有着突出的发展。但是, 在这个发展过程中, 很多企业依旧使用陈旧的政工工作内容和管理模式,与 时代的发展产生了很大的隔阂。现在工作的年轻人所接 触的知识和领域非常广泛, 思维方式比之前有了很大的 不一样,他们紧跟时代潮流,且拥有更高的思想追求, 希望 在工作岗位上通过自己不断的努力和探索获得同事、领 导的认可, 实现自我人生价值。因此, 企业要积极改变政 工工作的内容, 改进企业的管理考核方式、丰富员工的工 作内容, 在工作中充分体现员工的价值, 只有这样才能使 企业获得更好的经济效益, 实现其社会价值。

\section{3 企业政工队伍的综合能力不高}

确保政工工作能够顺利开展,离不开高素质、高能力 的政工队伍。企业只有拥有了综合能力较高的政工队伍 才能有效的促进政工工作的运转。但是, 以目前情况来 看,很多企业的政工工作人员的综合能力水平都不高,无 法满足政工工作的需求, 限制了政工工作的发展, 导致企 业管理水平落后,无法在众多企业中立足。

\section{4 工作开展的方式过于单一}

近几年,一些企业在开展政工工作过程中,取得的效 果并不是很理想。一些企业在进行思想政治讲座过程中, 对员工的思想政治教育采用灌输的方式, 或者采用简单 的激励制度。但是在实际工作中, 这样的工作方式并不能 很好的激发员工工作的积极性, 从而导致很难展开工作。 同时还有很多的企业对政工工作认识程度不够, 且受到 传统观念的影响, 缺乏创新意识, 不能顺应社会的发展需 求,而且在很多的企业工作中,采用的政工工作就是形式 上的,并没有实际作用,这也是企业政工工作所面临的巨 大挑战。

\section{5 缺乏人才的培养}

在市场经济下,企业竞争压力越来越大,企业为了保 持竞争力, 在经济市场发展中稳固地位, 部分企业在发展 的过程中过度重视企业经营管理, 忽略了企业对政工工 作人才的培养。从而导致很多企业政工工作人员的缺失, 缺乏专业的政工人才严重的影响了政工工作开展。此外,
因为没有相应的人才, 政工工作的开展没有专业的人员 进行指导和管理,严重影响政工工作的开展效果。

\section{6 政工队伍建设缺乏稳定性}

企业的政工工作人员需要熟练的掌握政工工作的 专业技能, 并在长期的工作中总结工作经验, 因此, 政工队 伍必须要保持政工工作开展的有效性, 才能更好的实现 工作效果。目前, 最大的难题就是企业政工人员的流动性 比较大, 导致政工队伍缺乏稳定性, 使政工工作长期且有 效的开展受到了影响。

\section{3 应对策略}

3.1 完善的企业奖惩体系

企业应该建立完善的奖惩制度，对企业有一定贡献 的人进行奖励, 这样才能激发工作人员的积极性, 让他们 产生自豪感, 让员工每一天都有饱满的精神, 有效的提高 企业工作效率。针对犯错误的员工要进行相应的惩罚, 让 每一位员工认识到工作的重要性。同时对没有进步的员 工注意观察, 适当的与他们沟通, 了解他们的思想并采取 有效的方法进行监督。

\section{2 高度重视人本管理模式}

企业能够正常运行离不开人, 工作人员对企业的可 持续发展, 起着至关重要的作用。因此, 在企业管理中, 要 重视人的主体地位, 以员工至上为根本原则。并且根据每 个人的实际工作水平及能力, 制定合理的职业发展计划 和企业对其工作人员的培养计划, 使员工能够感受到企 业对他们的重视, 感恩企业的付出, 同时, 还要注意观察每 个员工的内心想法, 通过不断的实践摸索, 建立完善、有 效的人才管理体系, 保障每名员工的合法权益, 从而有效 做好企业的政工工作。

\section{3 加强高素质政工队伍建设}

在企业中开展政工工作, 必须要有完善的工作标准, 这就要求企业必须具有一支素质较高和能力较强的政 工工作队伍。而且企业还要不断对这个队伍的素质水平 进行培训, 提高整个队伍的能力, 只有政工队伍的能力提 高, 才能更好的发挥他们在企业管理中的作用, 通过高效 的开展企业政工工作, 为企业获得更大的经济效益, 提高 市场竞争力。所以, 高素质政工队伍的建设, 直接影响企 业政治工作的开展情况

\section{4 强化政工人员自身的思想教育}

因为政工工作人员在开展相关政工工作的时候是 实践者,所以对实际政工工作来说,相关工作人员的思想 道德水平决定了这项工作的具体质量。为了使企业文化 与市场经济相适应并且共同发展, 也为了使政工工作思 想成为企业思想的宗旨, 企业必须要加强对政工人员的 思想政治的培养力度, 因为企业文化以及党政方针都是 通过政工人员传播出来的, 因此企业政工人员必须要重 
视社会主义核心价值观的培养。企业要积极培养政工人 员,为了使政工人员更好地为企业发展出力,企业要对政 工人员进行针对性的指导, 并定期组织他们进行相关的 培训, 只有文化和思想水平提高了才能更好地开展政工 工作,才能使他们作为宣传者保持良好的带头作用。

\section{5 工作方式进行及时的创新}

当前企业政工工作在开展过程中存在工作方式单 一等问题,基于此,企业需要紧跟时代的发展以及结合企 业自身的发展情况，对政工工作方式进行优化和创新。 首先,企业要明确政工工作面对的是全体工作人员,因此 为了更好的开展政工工作, 就需要充分掌握员工的特征, 把工作人员放在政工工作创新的首要考虑因素, 以此来 促进企业内部工作人员的凝聚力。其次, 企业还要把注 意力放在员工工作过程中的工作状态和内心的需求, 并 对其进行充分的调查和分析, 然后解决员工的需求, 让工 作人员深切的感受到企业的关怀, 促进其更好的为企业 服务。最后, 企业政工工作的创新可以从现代化的技术 人手, 结合数字媒体技术, 使政工工作能够引起企业员工 的注意力与兴趣, 让他们积极主动的参与到政工工作中, 促进政工工作得到顺利、有效的展开。

\section{6 充分运用网络技术}

随着互联网技术的发展,网络技术已经应用于社会 各个领域, 该技术也可以有效地引人政工工作中。具体 来说,企业可以在自己的网络平台上建立相关的思想政 治教育板块, 同时, 还可以将思想政治教育方向转移到移 动终端。由于现在的工作人员对这些网络技术都有很高
的兴趣，可以通过网络平台对工作人员进行思想政治教 育的引导,让工作人员更便利、更自主的进行学习。

\section{4 结语}

总而言之, 新时期企业政工工作中面临着很多的挑 战,虽然我国大多数企业已经意识到政工工作的重要性, 但是在实际工作中企业采用的工作方式比较落后, 而且 素质不高的政工工作人员,很影响企业的未来发展。为了 使企业能够在竞争市场中稳固地位, 就需要进一步加强 对政工工作的认识, 要求每一位员工积极参加培训活动, 进一步的提高综合素养和专业能力, 在实际工作中采用 新的工作模式,管理人员要落实好政工工作的具体事项, 采用新型的政工管理方式, 对企业的奖惩制度不断的完 善,提高工作人员主动性。

\section{[参考文献]}

[1]赵传磊.新时期企业政工工作面临的挑战和策略 探析 [J].办公室业务,2017(19): 19 .

[2]李呱,贾洪伟。分析新时期企业政工工作面临的挑 战和策略 [J].现代国企研究,2017(04):210.

[3]许智.分析新时期企业政工工作面临的挑战和策 略[J].东方企业文化,2015(11):173.

[4]屈聪荣.试论新时期企业政工工作面临的挑战和 策略[J].赤子(上中旬),2017,3(15):19.

[5]许昆生.浅析新时期企业政工工作面临的挑战和 策略 [J].现代企业文化,2017(06):30-31.

[6]孙国春.浅析新时期企业政工工作面临的挑战和 策略[J].现代企业文化,2015(07):25-26. 